\title{
HABILIDADES EDUCATIVAS Y REPRESENTACIONES SOCIALES DEL CINE DOCUMENTAL EXPERIMENTAL EN ESTUDIANTES UNIVERSITARIOS MEXICANOS
}

\begin{abstract}
MARTHA DE ALBA GONZÁLEZ
Universidad Autónoma Metropolitana-Iztapalapa, México. Profesora-investigadora del Departamento de Sociología, Licenciatura y Posgrado de Psicología Social. Doctora y Maestre en Psicología Social en la Ecole des Hautes Etudes en Sciences Sociales, Francia. Realizó una especialidad en estudios ambientales en la Université René Descartes, Francia. Es miembro del Sistema Nacional de Investigadores y co-fundadora de la Red Nacional de Investigadores en Representaciones Sociales (RENIRS). ORCID: https://orcid.org/0000-0002-1247-9122. E-mail: mdealba.uami@gmail.com
\end{abstract}

\section{MIGUEL ÁNGEL CASILLAS ALVARADO}

Universidad Veracruzana (Mexico). Profesor en la Maestría en Investigación Educativa. Doctor en Sociología por la Escuela de Altos Estudios en Ciencias Sociales de París. Licenciado en Sociología por la unam y maestro en Ciencias con Especialidad en Educación por el Die-Cinvestav-Ipn. Miembro del Sistema Nacional de Investigadores y profesor con Perfil deseable del Programa de Mejoramiento del Profesorado (Promep). ORCID: https://orcid.org/0000-0001-8194-7666. E-mail: mcasillas@uv.mx

\section{JEYSIRA DORANTES CARRIÓN}

Universidad Universidad Veracruzana (México). Profesora de Tiempo Completo Titular C y Coordinadora de la Especialidad en Estudios de Opinión. Imparte cursos en la Maestría en Antropología, en la Maestría en Didáctica de las Ciencias Sociales y en la Especialización en Estudios de Opinión. Doctora en Pedagogía por la Universidad Nacional Autónoma de México, maestra en Educación por la Universidad Veracruzana. Licenciatura en Pedagogía en la Universidad Veracruzana. Miembro de la Red Nacional en Investigaciones en Representaciones Sociales (renirs-cemers/México). ORCID: https://orcid.org/0000-0002-0633-5931. E-mail: jeysira@hotmail.com

\section{EULOGIO ROMERO RODRÍGUEZ}

Benemérita Universidad Autónoma de Puebla, México. Profesor de psicología. Doctor en Psicología por la Université de Caen Basse-Normandie, Francia. Maestre en Psicología Social y Trabajo en la Uniwersytet Adam Wickiewicz, Polonia, y Maestre en Psicología Social y Ambiental en la Université René Descartes, Francia. Co-fundador de la Red Nacional de Investigadores en Representaciones Sociales (RENIRS).E-mail: eulogio_romero@hotmail.com

\section{MARÍA EUGENIA RÍOS MARÍN}

Universidad Autónoma de Puebla, México. Trabaja en la Facultad de Psicología de Benemérita. Licenciatura en Psicología en la Benemérita Universidad Autónoma de Puebla. Posgrado en Psicología Social en la Ecole des Hautes Etudes en Sciences Sociales,

Francia. E-mail: genifrida@hotmail.com 


\section{HABILIDADES EDUCATIVAS Y REPRESENTACIONES SOCIALES DEL CINE DOCUMENTAL EXPERIMENTAL EN ESTUDIANTES UNIVERSITARIOS MEXICANOS}

El objetivo de este artículo es presentar los resultados de la investigación sobre la recepción de la trilogía Qatsi (Powaqatsi, Koyanisquatsi, Nagoyquatsi), obra de cine experimental de Reggio y Glass, por parte de estudiantes universitarios mexicanos. El estudio intercultural, en el que participan investigadores de varias universidades en México, es coordinado por Denise Jodelet en Francia. En este trabajo se pone énfasis en el análisis de los listados de asociaciones de palabras que escribieron 224 estudiantes de artes y de ciencias sociales después de la visualización de una síntesis de aproximadamente 40 minutos de la trilogía. Se analizan los resultados a partir de las representaciones sociales que los estudiantes elaboran para dar sentido a la síntesis fílmica, de acuerdo con su formación en artes (visión experta) y en ciencias sociales (visión no experta). Se interpretan los resultados en el contexto socio-cultural e histórico del país en el momento en que se aplicaron los cuestionarios en cada estado de la República Mexicana. Desde el punto de vista teórico, realizaremos una reflexión sobre la relación de las habilidades educativas y la teoría de las representaciones sociales, como herramientas conceptuales que nos permiten comprender las respuestas de la población estudiantil frente a la visualización de una obra artística compleja.

Palabras clave: Representaciones Sociales. Cine Experimental. Estudiantes. México. Trilogía Qatsi.

\section{EDUCATIONAL SKILLS AND SOCIAL REPRESENTATIONS OF EXPERIMENTAL DOCUMENTARY FILM IN MEXICAN UNIVERSITY STUDENTS}

The objective of this article is to present some results of the research on the reception of the Qatsi trilogy (Powaqatsi, Koyanisquatsi, Nagoyquatsi), experimental film by Reggio and Glass, by Mexican university students. The intercultural study, in which researchers from several universities in Mexico participate, is coordinated by Denise Jodelet in France. In this paper, emphasis is placed on the analysis of lists of word associations written by 224 students of arts and social sciences after the visualization of a synthesis of approximately 40 minutes of the trilogy. The results are analyzed from the social representations that the students elaborate to make sense of the filmic synthesis, according to their training in arts (expert vision) and social sciences (non expert vision). The results are interpreted in the socio-cultural and historical context of the country at the time the questionnaires were applied in each state of the Mexican Republic. From the theoretical point of view, we will reflect on the relationship of educational skills and the theory of social representations, as conceptual tools that allow us to understand the responses of the student population to the visualization of a complex artistic work.

Keywords: Social Representations. Experimental Films. Students. Mexico. Trilogy. 


\section{HABILIDADES EDUCATIVAS E REPRESENTAÇÕES SOCIAIS DE DOCUMENTÁRIO EXPERIMENTAL EM UNIVERSITÁRIOS MEXICANOS}

O objetivo deste artigo é apresentar os resultados de pesquisa sobre a recepção da trilogia Qatsi (Powaqatsi, Koyanisquatsi, Nagoyquatsi), trabalho no cinema experimental Reggio e Glass, por estudantes universitários mexicanos. $\mathrm{O}$ estudo cross-cultural, em que pesquisadores de diversas universidades no México envolvidos, é coordenado por Denise Jodelet na França. Neste artigo, a ênfase é colocada na análise de listas de associações de palavras escritas por 224 estudantes de artes e ciências sociais após a visualização de uma síntese de aproximadamente 40 minutos da trilogia. Os resultados são analisados a partir das representações sociais que os alunos elaboram para dar sentido à síntese fílmica, de acordo com sua formação em artes (visão pericial) e ciências sociais (visão não especialista). Os resultados são interpretados no contexto sociocultural e histórico do país no momento em que os questionários foram aplicados em cada estado da República Mexicana. Do ponto de vista teórico, refletiremos sobre a relação entre as habilidades educativas e a teoria das representações sociais, como ferramentas conceituais que nos permitem compreender as respostas da população estudantil à visualização de um trabalho artístico complexo.

Palavras chave: Representações Sociais. Cinema Experimental Estudantes México Trilogia Qatsi. 


\section{HABILIDADES EDUCATIVAS Y REPRESENTACIONES SOCIALES DEL CINE DOCUMENTAL EXPERIMENTAL EN ESTUDIANTES UNIVERSITARIOS MEXICANOS}

\section{Proyecto internacional sobre la obra cinematográfica de la trilogía Qatsi}

Este artículo presenta resultados preliminares de un estudio sobre las representaciones sociales que evoca la visualización de una síntesis de tres películas artísticas experimentales (trilogía Qatsi) por parte de una muestra de estudiantes universitarios mexicanos. Dicho estudio forma parte de una investigación internacional coordinada por la Dra. Denise Jodelet en Francia.

Jodelet (2015) estima que el arte es un tema poco explorado en el campo de estudio de la teoría de las representaciones sociales (TRS). Motivo por el cual, esta autora se dio a la tarea de reflexionar sobre el tema desde hace tiempo y de llevar a cabo un proyecto internacional sobre las representaciones sociales en torno a la Trilogía Qatsi (TQ), que es una obra de cine experimental conformada por tres películas realizadas por el cineasta Geodfrey Reggio y el compositor Philip Glass (Jodelet, 2016).

De acuerdo con Reggio, la Trilogía trata sobre cómo todo (política, educación, estructura financiera, la estructura del estado, el lenguaje, la cultura, la religión) existe dentro de la tecnología. "No es que usemos tecnología, es que vivimos la tecnología. La tecnología se ha hecho tan ubicua como el aire que respiramos".

Reggio intenta hacer presente y consciente el mundo contemporáneo a través de la comunicación de sentimientos despertados por el arte. Pretende generar una experiencia estética en el público mediante la combinación de la música de Philip Glass e imágenes, sin hacer uso del lenguaje hablado ni de personajes. Su intención es "llegar al alma de la gente" a través de la música.

La realización está guiada por la filosofía de la etnia Hopi. Retoma la cosmovisión de esta tribu Norteamericana para mirar al mundo tecnologizado a partir de tres figuras, representadas en cada uno de los filmes que componen la trilogía Qatsi, que significa vida en lengua Hopi. La primera película, denominada Koyaanisqatsi (1983), explora la vida desequilibrada; la segunda, Powaqqatsi (1988), presenta la vida consumida por el hechicero; la tercera, Naqoyqatsi (2002), evidencia la vida en guerra. 
Jodelet (2016) elige la TQ para analizar las representaciones sociales evocadas por el arte musical y visual porque presenta una "narración de nuestro tiempo", que está marcado por:

La pérdida de la naturaleza bajo la influencia de la tecnología, de la industrialización, la urbanización, ilustrada en Koyaanisqatsi (Vida desequilibrada1983). Las relaciones entre el norte y el sur en términos de dominación, de subordinación social y de alteración de modos de vida, en Powaqqatsi (Vida consumida por el hechicero, 1988) La globalización y sus consecuencias en las relaciones convertidas en conflictivas entre los hombres y su medio ambiente, los avances científicos y técnicos y los modos de existencia, la alienación económica y social y la tradición, hasta el punto de llegar a la catástrofe de la guerra, en Naqoyqatsi. (Vida en guerra, 2002)

Las escenas de las películas que componen la Trilogía Qatsi comunican un mensaje bastante crítico del mundo contemporáneo, bajo una estética contrastante que conduce al espectador a una experiencia estética compleja desde el punto de vista emocional y cognitivo. La velocidad de las imágenes y de la música marcan el ritmo de las sensaciones y del trabajo de comprensión de ésta. El público va creando su propia narrativa con los insumos artísticos que percibe. Algunas escenas de la naturaleza, de la vida cotidiana o de la tecnología son muy hermosas, algunas son bellas, pero crudas y dolorosas. La música de Philip Glass refuerza la estética de las imágenes, así como las emociones que éstas pueden evocar.

Los tres principales propósitos de esta investigación internacional sobre la TQ que enuncia Denise Jodelet (2016, p. 97) son:

En primer lugar, lo que fundamenta los propósitos de nuestra investigación: cómo acceder al pensamiento a partir de producciones artísticas que ponen en juego dimensiones sensibles y emocionales. En segundo lugar, cómo esta cuestión se va a definir con una indagación sobre la relación entre las obras de arte y las representaciones sociales. En tercer lugar, cómo una investigación sobre los operadores visuales y sonoros del pensamiento desemboca en los aportes al campo de estudio de los valores, así como en los de las representaciones sociales y de la cultura.

Para elaborar el estudio, Jodelet editó una síntesis de 40 minutos de la TQ para ser transmitida a estudiantes universitarios de 12 países, por equipos de investigadores participantes en el proyecto. Después de la visualización de la síntesis, se les solicitó que aplicaran un cuestionario con preguntas abiertas y cerradas sobre diversos temas relacionados con la TQ. En 
cada país, la muestra se encuentra dividida en estudiantes de arte, denominados "expertos"; y estudiantes de cualquier otra disciplina, llamados "no expertos".

\section{Habilidades educativas y representaciones sociales en torno a la síntesis de la TQ en estudiantes mexicanos}

El equipo de investigadores mexicanos que participamos en el proyecto, autores de este texto, nos hemos dado a la tarea de analizar algunos de los resultados del estudio sobre la TQ guiados por la exploración de la relación entre habilidades educativas, representaciones sociales y género. Las preguntas que guían este análisis son:

1. ¿Cuál es el campo de representación social sobre la TQ que construyen los estudiantes mexicanos después de haber visto la síntesis de las 3 películas?

2. ¿En qué medida las habilidades educativas de los estudiantes de arte contribuye a construir representaciones sociales distintas de la TQ con respecto a los estudiantes de ciencias sociales, quienes están menos familiarizados con el campo de las artes?

3. ¿Existen diferencias de género en la construcción de las representaciones sociales de la TQ por parte de los estudiantes universitarios participantes en este estudio?

Los creadores de la TQ, Reggio y Glass, buscaban que el significado de las películas dependiera de los espectadores, que cada uno creara una trama de significados e interpretaciones de cada film en función de su propia experiencia estética. En este trabajo consideramos que esos significados son representaciones sociales que los espectadores elaboran para interpretar las películas y dar sentido a la experiencia estética.

La teoría de las representaciones sociales (TRS) fue propuesta por Serge Moscovici desde mediados de los años cincuenta (Moscovici, 2013), aunque toma su forma más acabada en el libro El psicoanálisis, su imagen y su público (Moscovici, 1961). La TRS establece que los individuos, los grupos y las sociedades piensan a través de las representaciones que elaboran socialmente en el curso de su historia. Son sistemas de pensamiento que pueden ser estudiados como productos o como procesos de construcción social de la realidad (Jodelet, 1989, 1984), en distintos niveles 
de análisis: a) los individuos particulares que elaboran "teorías ingenuas" para comprender su mundo a partir de un bagaje cultural y social propio a la sociedad en la que están insertos; b) los grupos considerados como conjuntos de individuos que se congregan en torno a ideas o creencias comunes, por lo que comparten representaciones de la realidad; c) las sociedades complejas que pueden definirse dentro de los límites de un territorio y que a lo largo de su historia han generado una cultura propia, instituciones y sistemas simbólicos que los identifican. Sistemas simbólicos que fueron considerados por Durkheim como representaciones colectivas. Dichas representaciones sociales o colectivas son esquemas de pensamiento que guían las acciones en un contexto socio-histórico determinado.

Moscovici actualiza la noción de representación colectiva de Durkheim para generar una teoría que logre explicar el pensamiento social del hombre contemporáneo, confrontado con un mundo altamente tecnologizado y moderno. Durkheim vio en las representaciones colectivas sistemas de pensamiento tradicionales, relativamente estáticos, impuestos a los miembros de la sociedad por la fuerza coercitiva de las costumbres y de las creencias (Moscovici, 1989). Para Moscovici, estos sistemas de pensamiento son dinámicos, cambiantes, y coexisten con las nuevas formas de conocimiento que producen las sociedades modernas. Notablemente, destaca el papel de la educación masiva y de la socialización de la ciencia como categorías novedosas de pensamiento social. Las representaciones sociales dan sentido al mundo que nos rodea, echando mano de toda suerte de conocimientos, de creencias y de tradiciones, convirtiéndose en guías de acción y de comportamientos. Son una forma de pensamiento social construida por alguien (un actor individual o colectivo) en torno a un objeto representado. Un primer paso para el uso de esta teoría consistiría entonces en identificar cuál es el objeto de representación que nos interesa estudiar, así como los individuos, grupos o comunidades en quienes sería importante y pertinente observar la manera en que construyen representaciones de ese objeto específico. Cabe mencionar que para Moscovici no existe una separación entre sujeto-objeto, sino que se trata de una coconstrucción social de la realidad en relación con los otros, presentes o antepasados.

Este autor propone que las representaciones sociales operan a través de dos mecanismos de pensamiento, la objetivación y el anclaje, que les otorgan materialidad y que las ubican en un contexto histórico, social y cultural. El proceso de objetivación convierte una representación abstracta en algo concreto, permitiendo a los individuos y grupos expresar ideas o imágenes que toman forma y cuerpo a través del lenguaje, de prácticas o de esquemas comunicables socialmente. Por ejemplo, para expresar nuestra idea de lo divino, podemos recurrir a la iconografía propia a las religiones dominantes en el medio cultural al que pertenecemos, o a la religión que profesamos. En el dominio de la política, la idea de democracia, puede materializarse en actos concretos como el voto o la participación ciudadana. El proceso de anclaje asimila un objeto 
nuevo a representaciones sociales existentes, lo que nos permite comprenderlo e incorporarlo a nuestra realidad cotidiana. Lo nuevo, desconocido, pasa a formar parte de nuestras categorías de pensamiento previas, las enriquece y las modifica, del mismo modo que el objeto recién asimilado es transformado para ser comprendido. Existe una dinámica constante entre elementos novedosos o desconocidos y el pasado, a través del sistema de representaciones sociales pre-existentes. La memoria social juega un papel importante en el proceso de anclaje, ya que activa el bagaje sociocultural de quienes construyen una representación de un nuevo objeto. En su estudio clásico sobre las representaciones sociales del psicoanálisis, Moscovici (1961) muestra los mecanismos por los que distintos grupos de la sociedad francesa anclan al psicoanálisis en sus sistemas creencias, intereses e ideologías propias. De esta forma, el psicoanálisis, su práctica terapéutica, en tanto que concepto novedoso, es asimilado con el acto de la confesión religiosa; el lenguaje psicoanalítico pasa a formar parte del vocabulario corriente para explicar comportamientos y emociones propios y ajenos. Es frecuente encontrar frases hechas en las que es claro que la referencia psicoanalítica se integra al sentido común: "te traicionó el inconsciente", "tal persona se puso histérica", "fulano tiene un complejo de Edipo muy desarrollado", etc.

En este trabajo partimos de la idea de que los estudiantes universitarios participantes en este estudio tendrán una experiencia estética que tomará sentido a partir de representaciones sociales que cada uno elabora sobre la síntesis de la TQ. Tales representaciones estarán ancladas en su bagaje cultural, su orientación profesional y en el conocimiento adquirido en la formación universitaria en ciencias sociales y en las artes.

Aplicamos el cuestionario elaborado por Jodelet (2016) a 224 estudiantes en varias universidades y centros de investigación en México: la Benemérita Universidad Autónoma de Puebla, la Universidad Veracruzana, la Universidad Nacional Autónoma de México (sede Morelia), el Instituto Nacional de Antropología e Historia y la Universidad Autónoma MetropolitanaIztapalapa. Participaron 72 estudiantes "expertos" (mayoría relacionados con artes visuales) y 152 "no expertos" (la mayoría de psicología y ciencias sociales). 139 mujeres y 85 hombres.

Aquí presentamos los resultados del estudio exploratorio de la Pregunta 1: "Escriba 6 palabras o expresiones que le vengan inmediatamente a la mente después de esta proyección". Este ejercicio de asociación libre de palabras es muy utilizado en el campo de la teoría de las representaciones sociales para observar las ideas que conforman la representación del objeto de estudio de forma espontánea (Abric, 1995). 
El análisis está centrado en conceptos aislados, no en un discurso estructurado gramaticalmente. Esta primera aproximación nos que permitirá observar el campo representacional generado por la síntesis de la TQ.

Al observar diferencias en el campo representacional entre estudiantes de arte y de otras disciplinas presuponemos que la formación y orientación de los estudiantes universitarios de artes les ha dotado de ciertas habilidades de apreciación artística que determinaría las representaciones sociales que elaborarán en torno a la TQ. Explorar la diferencia en las representaciones sociales de la TQ de sexo femenino y masculino, supone que las formas culturales de ser hombres y mujeres en la sociedad mexicana podría marcar experiencias estéticas particulares a cada género.

Es importante mencionar que prácticamente ninguno de los 224 tenía conocimiento de las películas que conforman la trilogía. Elaboran sus representaciones sociales de la síntesis que les fue presentada sin referencias previas sobre la TQ.

\section{Palabras o expresiones que le vengan inmediatamente a la mente después de esta proyección}

Utilizamos el programa Iramuteq ${ }^{1}$ para el análisis de las asociaciones de palabras generadas por los 224 estudiantes participantes en el estudio. El programa arroja tres tipos de análisis: una nube de palabras organizadas en función de su frecuencia en el corpus, el árbol jerárquico descendiente del método Alceste y los grafos del análisis de similitud.

En la nuble de palabras que arroja el programa Iramuteq (ver imagen 1) observamos que aquéllas evocadas con mayor frecuencia son vida, guerra, naturaleza, destrucción, tecnología, humanidad, cambio, tristeza y violencia. Ello nos indica que el mensaje crítico a la vida tecnologizada del mundo contemporáneo que propone la TQ fue captado por los estudiantes universitarios participantes en nuestro estudio. El tema de cada una de las tres películas se ve reflejado en las asociaciones libres de palabras sin que los estudiantes hayan tenido conocimiento previo de ellas: la vida desequilibrada, la vida consumida por las fuerzas del mal (hechicero) y la vida en guerra.

\footnotetext{
${ }^{1} \mathrm{http}: / /$ iramuteq.org
} 
Image 1 - Nube de palabras (programa Iramuteq)

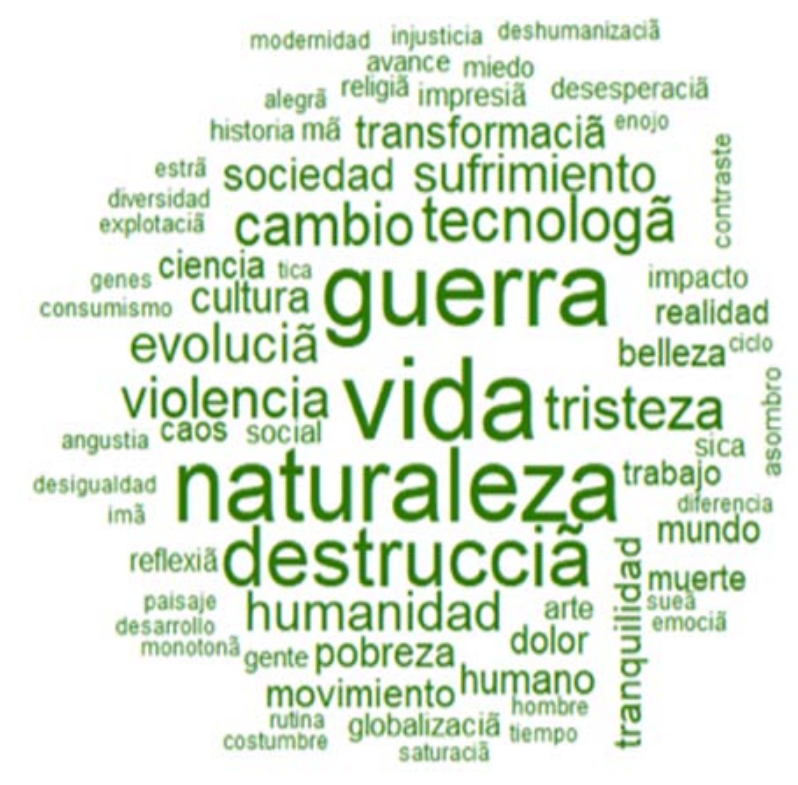

Fuente:

El método Alceste (Reinert, 1986; 1993; Alba, 2004) realiza un análisis jerárquico descendiente a partir del cálculo de co-ocurrencias de las palabras contenidas en unidades de contexto elementales (uce), las cuales están conformadas por sucesiones de 12 a 14 palabras, de acuerdo al parámetro estándar del programa. La finalidad es generar clases de palabras que se repiten en universos discursivos o semánticos similares. La interpretación de los resultados consiste en observar le vínculo que guardan las palabras al interior de cada clase, así como la relación entre las clases.

El análisis de clasificación jerárquica nos permitirá observar qué universos semánticos configura el conjunto de asociaciones de palabras generadas por la síntesis de la TQ. En la nube de palabras muestra que el mensaje de la TQ fue captado por los estudiantes. Ahora trataremos de ver de qué manera es captado, es decir, qué representaciones sociales subyacen al sentido del mensaje. 
Image 2 - Análisis jerárquico descendiente. Método Alceste

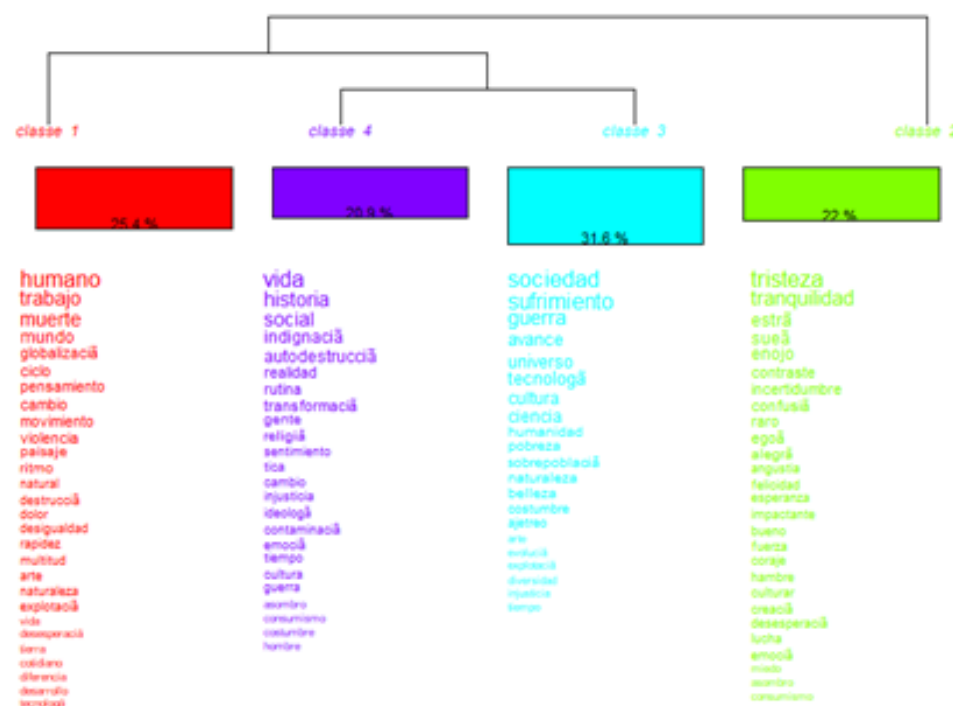

Fuente:

Como se puede observar en la imagen 2, en la parte superior de la clasificación jerárquica descendiente se bifurca elárbol en dos conjuntos de clases, que interpretaremos como dos universos semánticos diferenciados por el programa. El primero está compuesto por las palabras de la clase 2, que refieren a emociones contrastadas: por un lado, tristeza, enojo, coraje angustia, y por el otro, tranquilidad, alegría, felicidad y esperanza. El contraste emocional se encuentra asociado a la incertidumbre y la confusión, y a palabras que evocan lo onírico o extraño. Consideramos que esta clase expresa una contradicción implícita en la TQ entre el contenido doloroso de ciertas escenas, y la belleza de la música y de las imágenes.

El segundo universo semántico se relaciona con la vida humana y la transformación histórica de la sociedad. Se separa en tres clases (1, 3 y 4$)$ distintas. La clase 1 refiere a lo humano asociado al trabajo, a la globalización, al cambio, bajo la forma de violencia y destrucción de la naturaleza.

Las clases 3 y 4 aparecen estrechamente relacionadas en la última ramificación de la clasificación jerárquica descendiente, y remiten a dos aspectos de la vida transformada. Por un lado, el contenido de la clase 3 expresa los efectos perversos de la ciencia y la tecnología, ya que 
palabras como sociedad, cultura y humanidad, están asociados con los avances tecnológicos y científicos de forma negativa, con palabras como guerra, pobreza y sobrepoblación. Por el otro, en la clase 4, la vida parece transformada por la historia, la sociedad, la religión, la ideología y la cultura. Cambios que se asocian con la autodestrucción y con emociones y sentimientos de indignación e injusticia.

Si bien no hay diálogos ni personajes en la TQ, el análisis de las asociaciones libres de palabras evocadas por la TQ muestra que los estudiantes logran re-crear la narrativa que ha sugerido la obra: la transformación de la vida, de la humanidad y de la naturaleza por medio de la tecnología y de la economía globalizada.

Vemos que la mirada crítica de Reggio y Glass se introduce en esa narrativa, porque en las asociaciones de palabras, dicha transformación se relaciona con la guerra, la destrucción y la violencia, en detrimento de sociedades y culturas milenarias.

La representación pesimista del mundo contemporáneo que genera la TQ se ve acompañada de una contradicción emocional, propia de la experiencia estética creada al momento de presenciar la síntesis de la obra fílmica. La destrucción del ambiente natural y la violencia del medio social se retrata en secuencias de gran calidad artística, que transcurren al ritmo de la música sublime, hipnótica y enigmática de Philip Glass. La crueldad del mundo tecnologizado, regido por una economía inhumana, se nos presenta de forma hermosa, en una unión paradójica entre dolor y belleza.

El análisis jerárquico descendiente no evidencia diferencias entre expertos y no expertos en las asociaciones libres evocadas por la TQ. Ello significaría que las habilidades adquiridas por los estudiantes de arte no los dotan de una mirada experta de la TQ, ni de sus componentes artísticos. No deseamos sugerir que la formación universitaria en arte no es útil. La no diferencia del campo representacional entre estudiantes de arte y de otras disciplinas puede deberse a la desproporción de las muestras: 72 estudiantes "expertos" (mayoría relacionados con artes visuales) y 152 "no expertos" (la mayoría de psicología y ciencias sociales). También es posible que el mensaje político de la TQ tenga mayor peso en las representaciones sociales que los componentes estéticos del filme.

En cuanto a las diferencias por sexo, se observa que la variable sexo femenino contribuye especialmente a la clase 4, sugiriendo que las transformaciones sociales, históricas, ideológicas, religiosas y culturales de la vida, asociadas a la autodestrucción, a la indignación y la injusticia, fueron mayormente evocadas por las mujeres que por los hombres que participaron en el estudio. 
La variable sexo masculino no contribuye especialmente a ninguna de las otras clases, lo que significa que el vocabulario de los varones se refiere a los temas contenidos en todas las clases, sin enfocarse en un campo semántico en particular.

El análisis de similitud que realiza el programa Iramuteq reagrupa las palabras evocadas en función de su co-ocurrencia, sin tomar en cuenta el contexto de las palabras, como en el método Alceste, que realiza la clasificación a partir de las unidades de contexto elementales (UCE).

En este análisis de similitud, los conceptos repetidos con mayor frecuencia son generadores de las relaciones más fuertes entre las palabras, cuya co-ocurrencia las agrupa por grado de proximidad. Las analizaremos por grupos, de acuerdo a como se presentan en la imagen 3. El grosor de las líneas indica el grado de relación entre los conceptos.

La palabra guerra tiene una relación única con pobreza, caos, evolución, realidad e impacto. Se asocia fuertemente con otros conceptos nodales como vida, tecnología, destrucción y sufrimiento. Estas relaciones sugieren los efectos de la guerra y el papel de la tecnología en ella.

Image 3 - Análisis de similitud (Iramuteq)

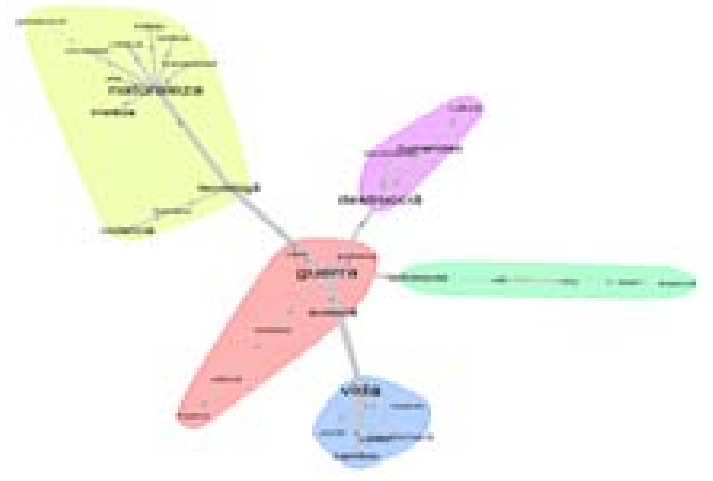

Fuente:

La noción de "vida" tiene una relación fuerte con la guerra, pero no con otros conceptos nodales. Su red semántica la componen transformación, cambio, social, mundo y muerte. Este conjunto de palabras indican que la vida es pensada como algo que cambia junto con el mundo y lo social en guerra y muerte. Pensaríamos entonces esta palabra en términos negativos; es decir, como la negación de la vida.

La palabra "tecnología" genera una red semántica compleja. Por un lado, se asocia con lo humano y la violencia. Por otro, con la palabra "naturaleza", que es el nodo de una red de 
conceptos que connotan emociones contrarias (tristeza vs tranquilidad), un aspecto estético (belleza y arte), aspectos socio-económicos (trabajo, sociedad, globalización) y una dimensión científica. Curiosamente, la ciencia aparece más frecuentemente relacionada con la naturaleza que con la tecnología en el análisis de similitud. Mientras que en la clasificación de Alceste tecnología y ciencia forman parte del mismo universo semántico.

El análisis de similitud evidencia una representación social de la tecnología que la coloca en dos vertientes: en una parecer estar al servicio de la violencia y de la guerra; en otra se relaciona con la sociedad a través del concepto de naturaleza. En ésta, la tecnología domina la naturaleza en beneficio de actividades laborales en sociedades globalizadas.

En el campo representacional de la TQ, la vida se encuentra más relacionada con la guerra y la muerte que con la naturaleza y lo humano. Finalmente, la palabra "destrucción" forma una red semántica autónoma, relacionada con movimiento, humanidad y cultura, al mismo tiempo que con guerra. Sugiriendo que el movimiento de la humanidad genera una cultura de la destrucción.

\section{Reflexiones finales}

El análisis de la asociación libre de palabras evocadas por la síntesis de la TQ muestra la eficacia del mensaje político-estético que pretendían transmitir sus creadores. Los diferentes métodos de análisis de las asociaciones de palabras muestran que los estudiantes universitarios encuestados recrean la narrativa crítica de la destrucción del mundo y de la naturaleza, así como de la transformación de la humanidad por la tecnología. Es una narrativa que se reafirma con las emociones contrapuestas evocadas por la combinación de la música minimalista de Philip Glass y las imágenes provocadoras de Godfrey Reggio.

No adelantaremos mayores conclusiones hasta no profundizar en el análisis de las otras preguntas del cuestionario. Por lo pronto se perfila la hipótesis de que los estudiantes de universidades públicas mexicanas tienden a identificarse con la crítica al capitalismo salvaje que retrata la TQ, a pesar de haber crecido en un mundo altamente tecnológico y de depender de la tecnología más que cualquier otra generación.

La TQ nos presenta la disyuntiva de negar la tecnología o seguir en ella disfrutando de sus bondades y padeciendo sus consecuencias. Se impone la pregunta: ¿Podemos subsistir en el mundo contemporáneo sin la tecnología? La vida ya nos parece impensable sin celulares, computadoras, la conexión a la internet, las redes sociales, las selfies y la última versión de Iphone.

Por otro lado, los resultados invitan a profundizar en el análisis de las diferencias por sexo para interpretar las representaciones sociales de TQ desde una perspectiva de género. Ello nos permitiría tratar de comprender por qué las mujeres de esta muestra ponen el acento en las transformaciones 
sociales, históricas, ideológicas, religiosas y culturales de la vida, y en la autodestrucción, la indignación y la injusticia. Del mismo modo, habrá que analizar con mayor detalle la inexistencia de diferencias de las representaciones sociales de la TQ entre estudiantes de arte y aquéllos inscritos en otras disciplinas.

\section{REFERÊNCIAS}

ABRIC, J. C. Prácticas y representaciones sociales. México: Ediciones Coyoacán, 1995.

ALBA, M. de. El método ALCESTE y su aplicación al estudio de las representaciones sociales: el caso de la ciudad de México. Papers on Social Representations, Vol 13, p. 1.1-1.20. 2004.

JODELET, D. Representación social: fenómenos, conepto y teoría. In S. Moscovici (Ed.), Psicología Social, Paidós, 1984.

JODELET, D. Madness and social representations: living with the mad in one French Community, Berkeley: University of California Press. 1991.

JODELET, D. Représentations sociales et mondes de vie. Paris: Editions des archives contemporaines, 2015.

JODELET, D. Sobre los operadores visuales y sonoros para compartir el pensamiento, Iztapalapa. Revista de Ciencias Sociales y Humanidades, núm. 81. Universidad Autónoma Metropolitana, México. 2016.

MOSCOVICI, S. La psychanalyse, son image et son public. PUF, France, 1961.

MOSCOVICI, S. Des représentations collectives aux représentations sociales, in D. Jodelet (ed.), Les représentations sociales. Paris, PUF, 1989.

REINERT, M. Un logiciel d'analyse lexicale: ALCESTE. Les cahiers de l'Analyse des Données, 4, pp. 471-484. 1986.

REINERT, M. Les mondes lexicaux et leur logique à travers l'analyse statistique d'un corpus de récits de cauchemars. Langage et société, déc. 1993.

Enviado em: 17 de julho de 2019

Apreciado em: 20 de julho de 2019

Inserido em: 01 de agosto de 2019 